\title{
At Berkeley, we recycle everything but $\mathrm{CO}_{2}$
}

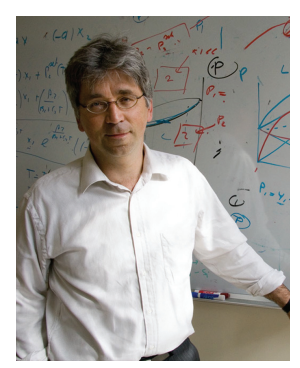

\author{
Berend Smit, Department of Chemical and \\ Biomolecular Engineering \\ Department of Chemistry \\ University of California, Berkeley \\ (Berend-Smit@Berkeley.edu) \\ http://www.cchem.berkeley.edu/molsim/ \\ personal_pages/berend/index.html
}

$\mathrm{R}$

esearch on carbon capture and sequestration (CCS) raises some eyebrows at Berkeley. After all, we are world famous for our recycling program, and here we are, researching the best way to create yet another landfill, this one filled with $\mathrm{CO}_{2}$. Why would we do that?

The argument goes even deeper. Students come to me and show me a small black cube, and argue: So you propose to dig up this coal, burn it, spend all the money to capture the $\mathrm{CO}_{2}$, and then store the $\mathrm{CO}_{2}$ as a gas in a geological formation. Is it not a much smarter idea to follow natureís way of sequestering carbon and leave the coal in the ground? Indeed many people argue that energy research should focus on solutions, not on mitigating problems. And yet the need for CCS can be made explicit if we look at Pacala and Socolowís famous energy wedges. ${ }^{1}$ There is no magic bullet to reduce carbon emissions; only a combination of different technologies can realistically stabilize carbon emissions. As our entire economy depends on fossil fuels, it is very unlikely that a new technology can phase out fossil fuels in the coming 20-40 years. Indeed, most scenarios on future energy consumption agree that, while the relative importance of fossil fuels will decrease, the absolute amount of fossil fuels used will continue to increase, because of the enormous growth in energy needs. In such a scenario, whether we like it or not, it is important to have large-scale CCS as an available viable option.

At this point, my students come with another argument. Once the $\mathrm{CO}_{2}$ is safely stored in geological formations, is this not wasting a valuable resource? Can we not use $\mathrm{CO}_{2}$ as a feedstock for the chemical industry? Bhown and Freeman $^{2}$ speculated on the consequences of this scenario. My interpretation of their ideas is that they propose to combine atom $\mathrm{ZZ}$ with $\mathrm{CO}_{2}$ to make $\mathrm{ZZCO}_{2}$, or Dreamium ${ }^{\mathrm{TM}}$. The chemistry is simple: we take an atom and have it react with $\mathrm{CO}_{2}$ to form our Dreamium ${ }^{\mathrm{TM}}$. The properties of Dreamium ${ }^{\mathrm{TM}}$ are such 
that everyone wants to buy it. Let us now also assume that Berkeley's chemistry department has developed this marvelous form of chemistry that allows it to synthesize Dreamium ${ }^{\mathrm{TM}}$ from any atom of the top 50 chemicals produced by the chemical industry worldwide. So we simply buy the world's production of the top 50 chemicals and use every atom to make Dreamium ${ }^{\mathrm{TM}}$. Clearly, we will make a lot of Dreamium ${ }^{\mathrm{TM}}$, much more than any product we make now. In addition, we will deplete the supply of the top 50 chemicals produced. Disappointingly however, if we do the bookkeeping, once we have produced all the Dreamium ${ }^{\mathrm{TM}}$ we possibly can, we will have captured at most only $20 \%$ of all $\mathrm{CO}_{2}$ being emitted. In other words, we generate so much $\mathrm{CO}_{2}$ that any product that uses $\mathrm{CO}_{2}$ as a feedstock will saturate any market and deplete all supplies - and still recycle no more than a fraction of all the $\mathrm{CO}_{2}$ we emit.

Finally, my students ask why we cannot upgrade $\mathrm{CO}_{2}$ to a fuel. The idea is to create a closed loop, burn fossil fuels, capture the $\mathrm{CO}_{2}$, and close the loop by upgrading the $\mathrm{CO}_{2}$ to a fuel. The problem here is that we need non-fossil energy for this to work. If we have this non-fossil energy anyway, might it not be a better idea to use this energy directly for electricity, and sequester the $\mathrm{CO}_{2}$ ?

Is the conclusion that we need to stop research on conversion of $\mathrm{CO}_{2}$ to useful products? If we put a price on carbon emission, $\mathrm{CO}_{2}$ will be a feedstock with a negative price. This will generate fantastic economic opportunities for our Dreamium ${ }^{\mathrm{TM}}$. But to make a significant dent in our carbon emissions, carbon capture and a $\mathrm{CO}_{2}$ landfill is our only option.

\section{References:}

1 Pacala S and Socolow R, Stabilization wedges: Solving the climate problem for the next 50 years with current technologies. Science 305:968-972 (2004).

2 Bhown AS and Freeman BC, Analysis and status of post-combustion carbon dioxide capture technologies. Environ Sci Technol 45:8624-8632 (2011). 